\title{
Improvement of Seismic Performance of Beam-column Connection With Replaceable Drilled Attachment Parts
}

\author{
Mehdi Vajdian ${ }^{1 *}$, Ali Parvari², Mohammad Afzali \\ 1 Department of Civil Engineering, Aligudarz Branch, Islamic Azad University, PO Box: 68618-159, Aligudarz, Iran \\ 2 Department of Civil Engineering, Khomein Branch, Islamic Azad University, PO Box: 38815-177, Khomein, Iran \\ ${ }^{3}$ Graduated of Civil Engineering, Shahid Rajaee Teacher Training University, PO Box: 16785-163, Tehran, Iran \\ * Corresponding author, e-mail: m.vajdian@iau-aligudarz.ac.ir
}

Received: 06 November 2019, Accepted: 26 July 2020, Published online: 16 September 2020

\begin{abstract}
Since beam-column connection plays a prominent role in steel structures, by designing and constructing it properly, the structure will behave better and safer. Numerous researches are carried out on steel connections, like Reduced Beam Section (RBS) and Drilled Flange Connection (DFC). Each connection has advantages and disadvantages. This study evaluates the effect of different connections on behavior of steel moment frames. The connections evaluated in this study are as follows: Connection with drilled attachment part, drilled connection with identical and variable diameter, beam connection with reduced flange. This connection contains one or two replaceable drilled parts that are mounted in connection place. The connection is modeled using the ABAQUS software. Finally, Finite Elements Modeling (FEM) is utilized to calculate the stiffness of each connection. According to the results of the newly introduced connection in terms of energy absorption and ductility is the best example and among the drilled models investigated in this study, drilled connection with variable diameter (proportional to diamond shape) which performed better in terms of behavior and performance than the other perforated models. Also, reduced flange connection ranks third in performance. In proposed connection the plastic hinge is formed at the attachment part of the connection that is replaceable, also there is little damage to the beams and columns, which is one of the main benefits of this connection.
\end{abstract}

Keywords

ABAQUS, connection, rotation-moment diagram, pushover, drilled flange, proposed connection with attachment parts

\section{Introduction}

A very common damage in steel structures that is caused by earthquake is failure in beam-column connection. This failure may lead to collapse of floors and loss of strength in building. Steel moment frames were considered as a ductile and strong structure among other structural systems until the 1994 Northridge earthquake. The Northridge earthquake in January 1994 caused great damages to steel moment frame structures with welded beam column connection, and it was because of plastic hinge formation on column face. The 1994 Northridge earthquake was a turning point in the design and construction of Welded Un-reinforced Flange (WUF). Failure of Welded Un-reinforced Flange (WUF) connection in Northridge earthquake caused destruction of steel buildings and death of many people [1]. It made many researchers and engineers to investigate the seismic performance of these connections [2]. In order to improve the seismic behavior, flexibility, and performance assurance of connections, two strategies were introduced after the Northridge earthquake: Column reinforcement and beam connection weakening. In this strategy, beam section is weakened at a specified distance from column face until the plastic hinge move away from the column face.

By reducing the flange area, plastic capacity of beam section will be reduced. And it will lead to formation of plastic hinge away from column face, which resist against damage in connection zone. By reducing the plastic capacity, in-plane stiffness of the beam will reduce and lead to reduction of section lateral torsion strength near that zone, therefore, buckling will turn into a critical problem.

According to several investigations, tri-axis stress in beam flanges full penetration weld will lead in rapid failure of weld line near the beam flange before any yielding and plastic deformation of beam [2]. In order to modify 
this connection, reduced connections are developed for reliable and functional solutions to avoid fracture in beam-column welded connections [3]. Bending connections of Reduced Beam Section establish an intentional weak point in beam flange which produce the proper fuse for reducing the stress of welded connection in column.

Crisan and Dubina [4] studied and analyzed reciprocal bending-shear effect on short steel connections with section reduction. Two beams with different lengths were investigated experimentally and numerically, in order to show the short beams plastic deformation mechanism in steel frames. Results indicated that plastic deformation would increase by increment of beam aspect ratio. In experimental and numerical investigations of Tahamouli Roudsari et al. [5] the behavior of reduced section IPE with diagonal web stiffeners was evaluated. Some researchers could delay the web buckling by adding web stiffeners to reduced area and increased the flexibility of connection. By investigating several experimental and numerical models, it is obtained that using diagonal stiffeners will stabilize the Hysteresis graph and also delay the destruction.

Tahamouli Roudsari et al. [6] carried out an experimental and numerical research about reduced beam section IPE by using box-stiffeners. Reduction of beam width in RBS will potentially increase the lateral buckling connection probability. The box-stiffeners were introduced to overcome this problem. Results showed that stiffeners increase the connection ductility to a large extent without modifying its resistance. Montouri and Sagarese [7] used steel RBS to increase ductility of wooden beams. They introduced a set of criteria for assuring the formation of plastic hinge. Finally, a design chart was designed to be used for the same connections.

Uang and et al. [8] suggested the application of drilled beam flanges for beam section reduction. Using holes in beam flange will reduce construction costs and also ease the construction of RBS connections. Numerous researches showed that holes with identical diameter don't correspond to the special bending frame provisions $[9,10]$. In further studies researches used holes with variable diameter and special arrangements. And results showed that these connections can correspond to bending frames [11-13].

Vajdian et al. [14], investigation of Seismic Performance of (RBS) and Drilled Flange Connection Containing rhombus Shaped hole in steel moment frames. In this paper, simple connections, Reduced Beam Section, drilled flange connection, and drilled connection with a variable diameter corresponding to the diamond-shaped hole were evaluated. A frame was modelled in SAP based on the stiffness calculated in ABAQUS. In this research, the hinge is formed in the middle of the holes.

Maleki et al. [15], studied on seismic fragility assessment of SMRFs with drilled flange connections using ground motion variability. DF, RBS, WUF connections and Panel Zone were numerically modeled. These models were applied to analyze low-and high-rise buildings. Incremental Dynamic Analysis (IDA) process was utilized to evaluate the effects of DF connection on structural seismic response of SMRFs. The results showed that the seismic demand of SMRFs with DF and RBS connections were so similar, specifically for low-rise buildings. Likewise, SMRFs with DF connection provided up to $43 \%$ higher seismic demand in high-rise buildings compared to RBS connection.

Özkılıç [16] describes a new type of replaceable fuse for moment resisting frames. Column-tree connections with beam splice connections were frequently preferred in the moment resisting frames since they eliminate field welding and provide good quality. In the column-tree connections, a part of the beam was welded to the column. In this research, a replaceable reduced beam section connection was proposed in order to eliminate welding process and facilitate assembly at the site.

The reduced beam section connection is difficult and costly because of 4 sections in flange, especially in current structures. Also, other beam flange reduction connections like DFC are investigated which improve the ductility connection, lessen the costs, and ease construction. Connection ductility differs according to connection type and plastic hinge placement and also seismic demand which hinge applies to connection. Location, length, shape, and characteristics of plastic hinge impact directly on connection in steel moment frames. The objective is to find required ductility, proper energy depreciation, and resistant connection with high stiffness. Beam flange reduction by drilled holes helps to shift the plastic hinge zone from column face and increases the ductility of connection.

In this study, we compared three methods include beam-column connection with replaceable attachment part at the connection place, attenuating the beam by drilling the flange DFC (Drilled Flange Connection) and beam attenuation by circular cut in flange, RBS (Reduced Beam Section) that is the most recent method. This paper introduces a connection with new attachment parts, which, if it collapses it can be replaced with a similar one. The connection can be easily mounted to the beams and columns 
with screws, the other benefits of this connection can be its economical. The attachment parts are mounted parallel to the beam flanges at the top and bottom, these parts are symmetrical. Holes were drilled symmetrical and in two rows to allow the hinge to form at the attachment part. In connection with attachment part, the load capacity of the beam was increasing due to the stress path at first is in the attachment part and then transferred to the beam flange. In this study, in addition to connection with an attachment part, the effects of connections with reduced beam flanges and drilled flanges with different diameters and connection with diamond shaped holes has also been studied which is obtained from the reduced flange beam pattern. The diamond is based on RBS and the shape of these holes is perfectly symmetrical and the small diameter hole is selected at the beginning of model and the larger diameter hole in the middle of model. In all models several different types of beam and column and layout pattern have been studied. In general, in this paper, for the connection with attachment part 4 models, for the RBS connection 4 models, for the DFC connection 16 models, and for the diamond connection 4 models have been studied. In total, about 28 different models of connections have been evaluated. Finally, after obtaining the specifications of the connections, the accurate behavior of these types of connections in the steel moment frame is investigated and the results are compared.

\section{Fact checking}

To evaluate the validity of the models in study, a research which is done by Fanaei and Moghadam [17] has been used. The process of performing and comparing the model is as follows.

The model is presented in Fig. 1.

The selected model was three-dimensional. The model name is TSDF-4. The thickness and width of the beam are 15 and $180 \mathrm{~mm}$, respectively. The beam and column features are shown in Table 1.

The three-dimensional finite element model of the solid element type is an eight-node C3D8R reduced integral. The mesh has been a regular quadrilateral. The loading is cyclically inserted at the end of the beam flange.
The concrete used was self-compact concrete (SCC) with a compressive strength of $35 \mathrm{MPa}$.

The loading is shown in Fig. 2.

This figure shows the loading cycle that is applied to the end of the beam. This loading is calculated based on the reciprocating cycles proportional to the relative displacement of the drift. In this way, in each cycle, a percentage of this displacement enters the end of the beam.

As it is presented in Fig. 3, the fact checking model is more accurate than the model in referred paper.

\section{Description of studied models}

In this section we describe the models studied.

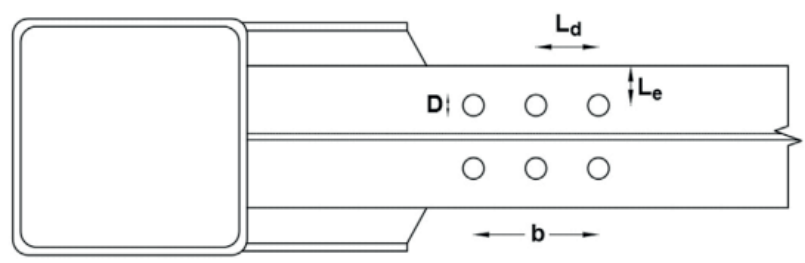

Fig. 1 Model selected for verification [17]

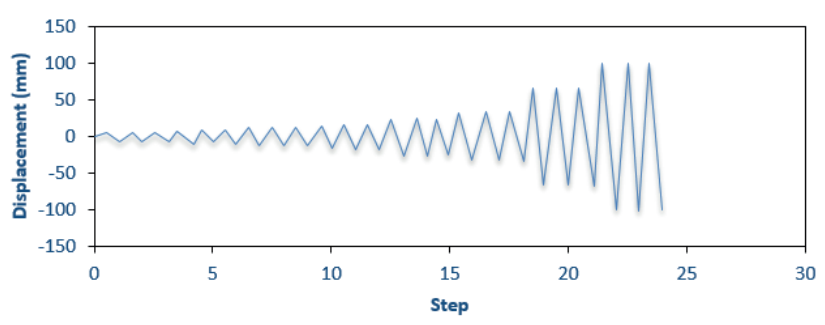

Fig. 2 Loading history for proof-of-concept test [17]

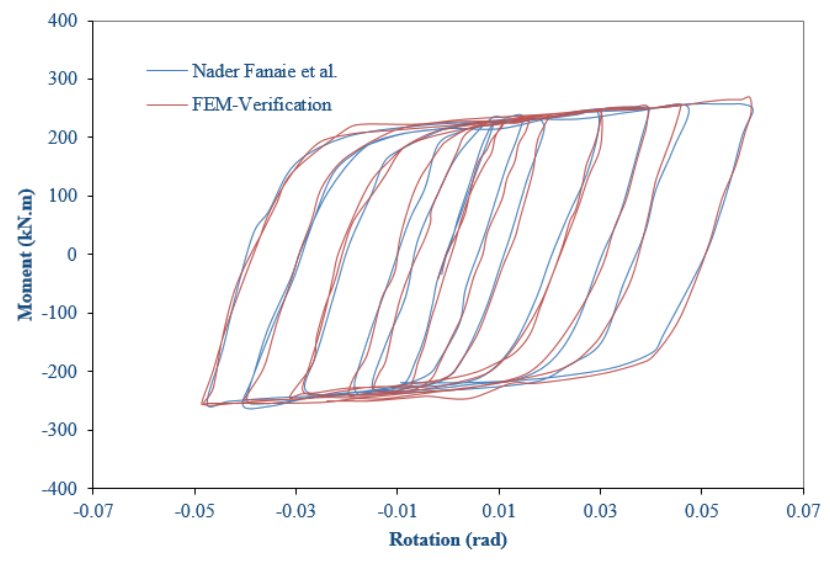

Fig. 3 Rotation-moment diagram in the paper and the model of validation

Table 1 Specifications of beams and columns used [17]

\begin{tabular}{|c|c|c|c|c|c|c|c|c|}
\hline Model & $\begin{array}{c}\text { Number of } \\
\text { holes }\end{array}$ & $\begin{array}{l}\text { Diameter of smallest } \\
\text { hole (Dmin) }\end{array}$ & $\begin{array}{l}\text { Diameter of biggest } \\
\text { hole (Dmin) }\end{array}$ & $\begin{array}{l}\text { Diameter between the } \\
\text { first and last hole (b) }\end{array}$ & $\begin{array}{l}\text { Center to center } \\
\text { distance of holes }\end{array}$ & $\mathrm{Dmin} / \mathrm{bf}$ & $\mathrm{Dmax} / \mathrm{bf}$ & $\mathrm{b} / \mathrm{db}$ \\
\hline TSDF-4 & 4 & 18 & 27 & 210 & 70 & 0.1 & 0.15 & 0.7 \\
\hline
\end{tabular}



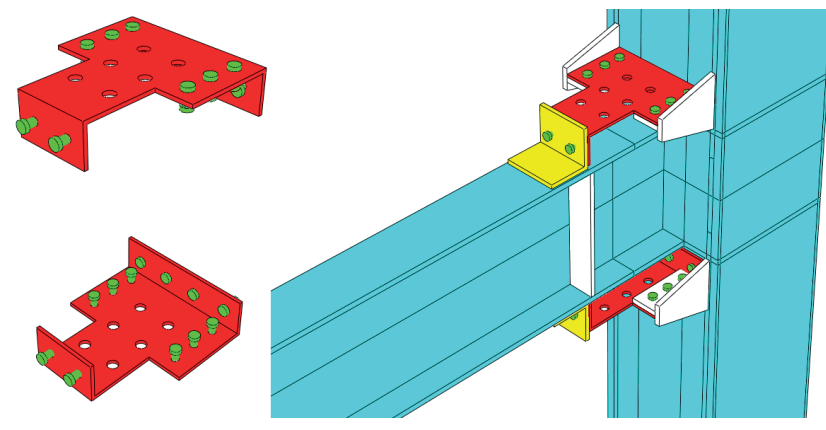

a) with one attachment part

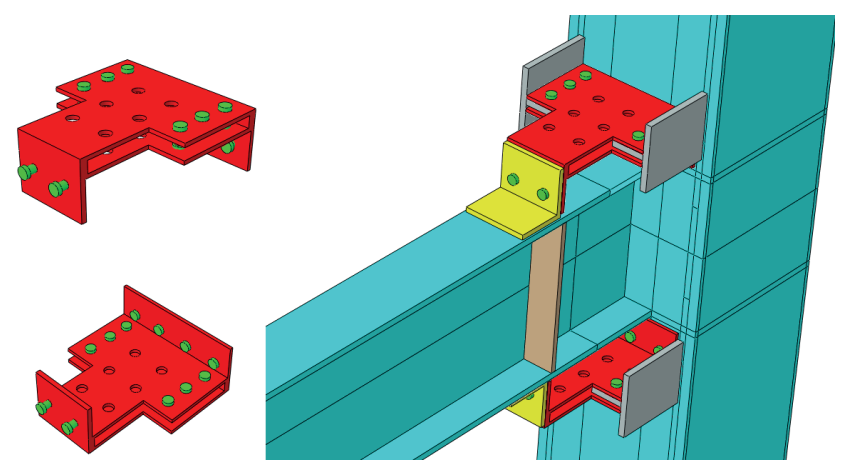

b) With two attachment parts

Fig. 4 New attachments at beam-column connection

\subsection{Proposed connection with attachments}

Damage at the beam-column connection is one of the major issues in structures; forming a plastic hinge and failure is always observed at the connection. Control of this failure is always presented in a variety of ways, including RBS and DFC, but the disadvantages of these methods are the damage to the beam and its deterioration, which is economically costly. In this article, by introducing a proposed connection with attachments, the connection can be easily re-used by replacing the damaged part.

In the proposed connection, two cross parts are used at the connection, as shown in Fig. 4. These two parts are cross-linked due to the reciprocating motion of the earthquake behavior and more energy absorption and control of compressive and tensile stresses due to the moment at the connection. The thickness of these parts is selected according to the thickness of the beam flange and less than it.
The models investigated for this connection are shown in Table 2. For naming in the Table 2, the first letter ND means the proposed connection; the numbers 2 beside it denote the number of part on the attachment.

Presuming that plastic deformation in the proposed structural system is limited to the proposed connection with attachments, this system is capable of carrying the moment from the beam. At the full plastic state, defined at the yielding of the proposed connection with attachments, the theoretical beam shear force $\left(Q_{y}\right)$ and the moment at the column face $\left(M_{y}\right)$ are expressed by:

$Q_{y}=\frac{P_{y} d_{s t}}{l_{b 1}}$,

$M_{y}=Q_{y} \cdot l_{b}=\frac{P_{y} d_{s t} l_{b}}{l_{b 1}}$.

At the ultimate state, the maximum beam shear force $\left(Q_{u}\right)$ and the moment at the column face $\left(M_{u}\right)$ corresponding to the maximum strength of the proposed connection with attachments are computed by:

$Q_{u}=\frac{P_{u} d_{s t}}{l_{b 1}}$,

$M_{u}=Q_{u} \cdot l_{b}=\frac{P_{u} d_{s t} l_{b}}{l_{b 1}}$.

The width of attachment plate is selected according to width of beam flange. So that it can be mounted parallel to the flange. The following relation is used to calculate the thickness of an attachment part:

$t_{P L}=\frac{M_{u} \times 10^{6}}{\varphi \times d \times b_{p l} \times F_{y}}$

In the above relation $\varphi$ equals one, $b_{p l}$ is the width of the attachment plate that is better to choose it appropriate with the beam width, $d$ is the distance between the center of the upper and lower attachment plate $s, F_{y}$ is the yield stress of the attachment plate.

Table 2 New attachments at beam-column connection

\begin{tabular}{|c|c|c|c|c|c|c|}
\hline Model & Column (mm) & Beam & Additional thickness & The diameter of the hole (mm) & Hole distance $(\mathrm{mm})$ & Number of holes \\
\hline ND-C25-B36 & $250 \times 250 \times 10$ & IPE360 & 12.7 & 30 & 218 & 3 \\
\hline ND-C50-B45 & $500 \times 500 \times 12$ & IPE450 & 14.6 & 30 & 218 & 3 \\
\hline ND2-C25-B36 & $250 \times 250 \times 10$ & IPE360 & 12.7 & 30 & 218 & 3 \\
\hline ND2-C50-B45 & $500 \times 500 \times 12$ & IPE450 & 14.6 & 30 & 218 & 3 \\
\hline
\end{tabular}


The connection is modeled using ABAQUS Finite Elements software. The connection is tested with a stiffener. Fig. 5 presents the proposed connection.

\subsection{Drilled flange beams}

In this part, different drilling methods are evaluated. First, the number and spacing of holes are considered variably but the diameter of holes is identical. In the next part, a drilling shape arrangement is suggested based on Reduced Beam Section (RBS), and it is named diamond-shaped because of its similarity with diamond.

\subsubsection{Drilled connections with identical diameter and various spacing and number of holes}

Table 3 shows drilled flange beam-column connection models. It is named DFC, Drilled flange connection model. All presented parameters in Table 3 are based on millimeter unit. Diameter and number of holes are variable. The letter DFC is used to denote the drilled cross-section followed by that a number representing the number of holes in the cross-section. In some models, two numbers are presented, the first is the number of holes and the second is the diameter of the hole. In the following, the column and beam cross sections are named with $\mathrm{C}$ and $\mathrm{B}$, respectively.

Fig. 6 presents the hole shape elevation and its position on beam.

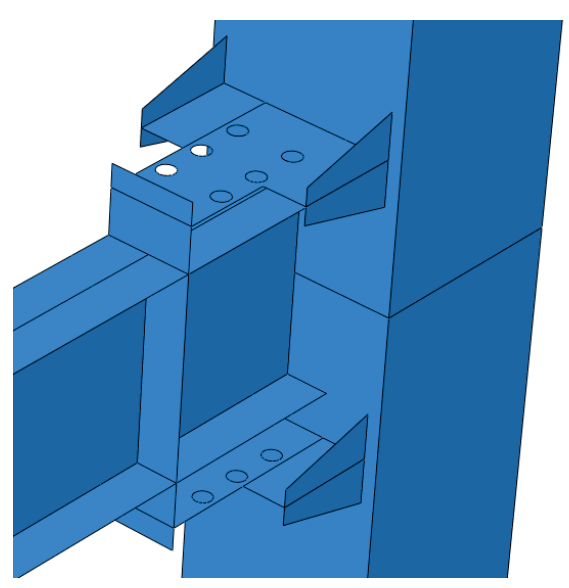

Fig. 5 Beam-to-column Proposed connection

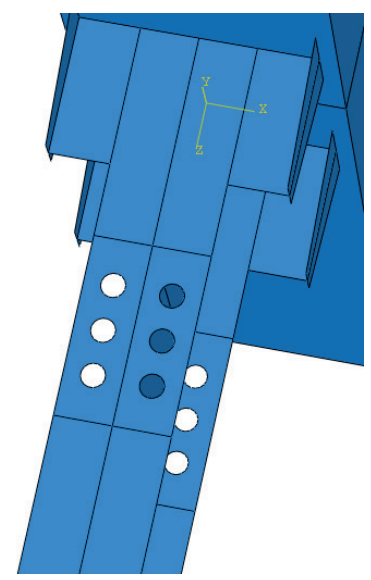

Fig. 6 Pattern of hole placement on DFC beam wing

Table 3 Drilled flange beam-column connection models

\begin{tabular}{|c|c|c|c|c|c|c|}
\hline Name & Column (mm) & Beam & $\begin{array}{l}\text { The first hole distance } \\
\text { from the column }\end{array}$ & $\begin{array}{l}\text { Diameter of holes } \\
\text { (mm) }\end{array}$ & $\begin{array}{l}\text { Hole distance } \\
\quad(\mathrm{mm})\end{array}$ & Number of holes \\
\hline DFC-1-C25-B36 & $250 \times 250 \times 10$ & IPE360 & 270 & 30 & --- & 1 \\
\hline DFC-3-30-C25-B36 & $250 \times 250 \times 10$ & IPE360 & 195 & 30 & 75 & 3 \\
\hline DFC-3-40-C25-B36 & $250 \times 250 \times 10$ & IPE360 & 195 & 40 & 75 & 3 \\
\hline DFC-4- C25-B36 & $250 \times 250 \times 10$ & IPE360 & 195 & 30 & 75 & 4 \\
\hline DFC-1-C25-B30 & $250 \times 250 \times 10$ & IPE300 & 270 & 30 & --- & 1 \\
\hline DFC-3-30-25-C25-B30 & $250 \times 250 \times 10$ & IPE300 & 195 & 30 & 75 & 3 \\
\hline DFC-3-40-C25-B30 & $250 \times 250 \times 10$ & IPE300 & 195 & 40 & 75 & 3 \\
\hline DFC-4-C25-B30 & $250 \times 250 \times 10$ & IPE300 & 195 & 30 & 75 & 4 \\
\hline DFC-1-C22-B27 & $220 \times 220 \times 10$ & IPE270 & 270 & 30 & --- & 1 \\
\hline DFC-3-30-C22-B27 & $220 \times 220 \times 10$ & IPE270 & 195 & 30 & 75 & 3 \\
\hline DFC-3-40-C22-B27 & $220 \times 220 \times 10$ & IPE270 & 195 & 40 & 75 & 3 \\
\hline DFC-4-C22-B27 & $220 \times 220 \times 10$ & IPE270 & 195 & 30 & 75 & 4 \\
\hline DFC-1-30-C50-B45 & $500 \times 500 \times 120$ & IPE450 & 270 & 30 & --- & 1 \\
\hline DFC-3-30-C50-B45 & $500 \times 500 \times 120$ & IPE450 & 195 & 30 & 75 & 3 \\
\hline DFC-3-40-C50-B45 & $500 \times 500 \times 120$ & IPE450 & 195 & 40 & 75 & 3 \\
\hline DFC-4-C50-B45 & $500 \times 500 \times 120$ & IPE450 & 195 & 30 & 75 & 4 \\
\hline
\end{tabular}




\subsubsection{Drilled connection with variable diameter (diamond-shaped) - proposed model}

Table 4 shows drilled flange beam-column connection models. It is named DFCV. Numbers are used to make distinction between beam and column, and the rest of the names are presented by numbers.

The drilled connection assumed in Table 4 is used for Reduced Beam Section method correspondingly. The shapes of holes are all symmetrical. Small diameter holes are chosen for bottom of model, and holes in the middle are the greatest, and in the end the diameter is reduced again, this connection is similar with diamond therefore is named diamond-shaped. The connection shown in Table 4 is based on a diamond-shaped pattern as presented in Fig. 7 [14].

\subsection{RBS models}

Table 5 presents the models. 'Reduced beam section' is used for naming the samples. RBS stands for Reduced beam section. IPE beams and box columns are used in models. Dimensions and spacing for shears in flanges are based on millimeter unit. Letters and numbers are used like $\mathrm{C} 25$ to show column along with names, which $\mathrm{C}$ stands for column, and 25 presents $250 \times 250 \times 10$ box section. The last number and letter is for beam section. B36 means beam with IPE360. Fig. 8 presents each beam connection in one figure.

\section{Modeling process}

A 6 story frame model is evaluated. Steel no. ST52 is used as materials. Fig. 9 presents the applied steel stress-strain graph.

All stories are 3 meters high. All frames contain 3 spans and each opening is 5 meters wide. Table 6 shows the steel properties. Soil Type III is used for structure placement. moment frame of intermediate type is used in the process.

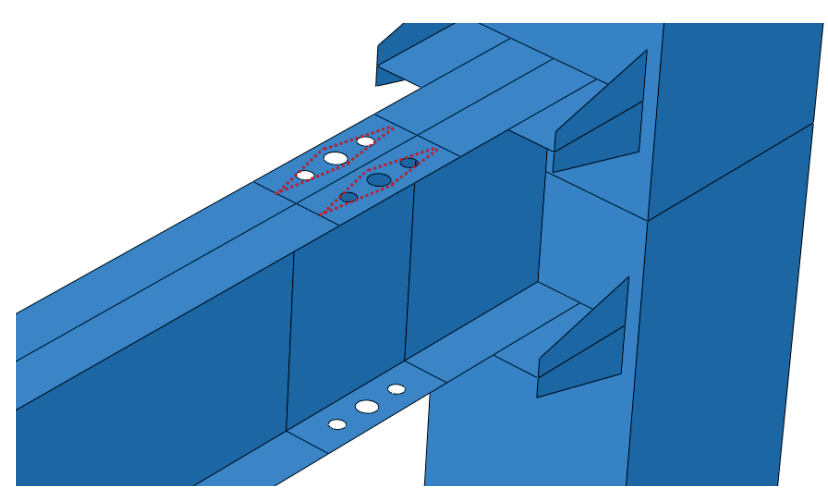

Fig. 7 Show cross section with provided holes [14]

Table 5 The sample model and RBS

\begin{tabular}{lccccc}
\hline Name & Columns (mm) & Beam & $\begin{array}{c}\mathrm{a} \\
(\mathrm{mm})\end{array}$ & $\begin{array}{c}\mathrm{b} \\
(\mathrm{mm})\end{array}$ & $\begin{array}{c}\mathrm{c} \\
(\mathrm{mm})\end{array}$ \\
\hline RBS-C25-B36 & $250 \times 250 \times 10$ & IPE360 & 100 & 235 & 25 \\
RBS-C25-B30 & $250 \times 250 \times 10$ & IPE300 & 100 & 235 & 25 \\
RBS-C22-B27 & $220 \times 220 \times 10$ & IPE270 & 100 & 225 & 25 \\
RBS-C50-B45 & $500 \times 500 \times 12$ & IPE450 & 120 & 345 & 40 \\
\hline
\end{tabular}

Dead surface load of $600 \mathrm{~kg} / \mathrm{m}^{2}$ and live surface load of $200 \mathrm{~kg} / \mathrm{m}^{2}$ is considered. imposed load amount of $2400 \mathrm{~kg} / \mathrm{m}$ and live load of $800 \mathrm{~kg} / \mathrm{m}$ on columns is calculated. IPE beams and box columns are used in models. Table 7 shows the models with specified sections for each element.

Connection stiffness is modeled and link element is used by considering the calculated connection stiffness. All modeling is done in SAP2000. Nonlinear (pushover) static analysis of the frame is carried out. In order to do nonlinear static analysis, lateral load is applied to structure based on first mode and uniformly. Moment hinge type of M3 is used for beams. Interactive compressive hinge and bending moment of PM2M3 is used for columns.

Loading pattern is imposed to connection based on ATC-24 [18].

Table 4 Connect with drilled sections like diamond

\begin{tabular}{|c|c|c|c|c|c|c|c|c|}
\hline Name & Column (mm) & Beam & $\begin{array}{c}\text { The first hole } \\
\text { distance from the } \\
\text { column }\end{array}$ & $\begin{array}{l}\text { Diameter of the } \\
\text { first hole (mm) }\end{array}$ & $\begin{array}{l}\text { Diameter of } \\
\text { the second hole } \\
(\mathrm{mm})\end{array}$ & $\begin{array}{c}\text { Diameter of } \\
\text { third hole }(\mathrm{mm})\end{array}$ & $\begin{array}{l}\text { Hole distance } \\
(\mathrm{mm})\end{array}$ & $\begin{array}{c}\text { Number of } \\
\text { holes }\end{array}$ \\
\hline $\begin{array}{l}\text { DFCV- } \\
\text { C25-B36 }\end{array}$ & $250 \times 250 \times 10$ & IPE360 & 195 & 30 & 40 & 30 & 75 & 3 \\
\hline $\begin{array}{l}\text { DFCV- } \\
\text { C25-B30 }\end{array}$ & $250 \times 250 \times 10$ & IPE300 & 195 & 30 & 40 & 30 & 75 & 3 \\
\hline $\begin{array}{l}\text { DFCV- } \\
\text { C22-B27 }\end{array}$ & $220 \times 220 \times 10$ & IPE270 & 195 & 30 & 40 & 30 & 75 & 3 \\
\hline $\begin{array}{l}\text { DFCV- } \\
\text { C50-B45 }\end{array}$ & $500 \times 500 \times 12$ & IPE450 & 195 & 30 & 40 & 30 & 75 & 3 \\
\hline
\end{tabular}




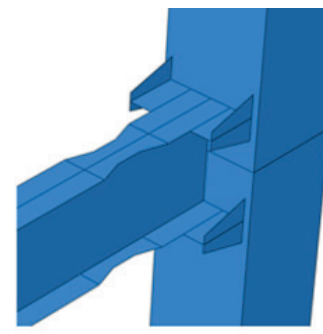

RBS-C50-B45

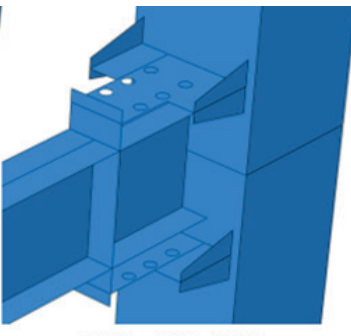

ND -C50-B45

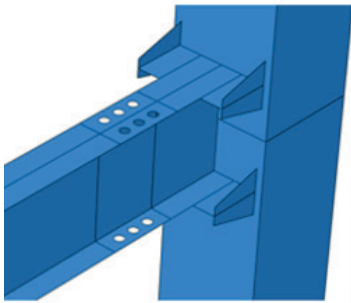

DFC-3-40-C50-B45

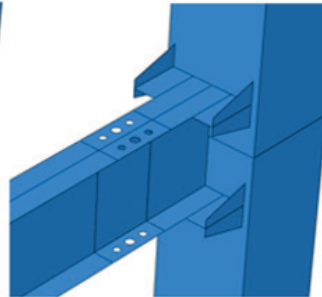

DFCV-C50-B45

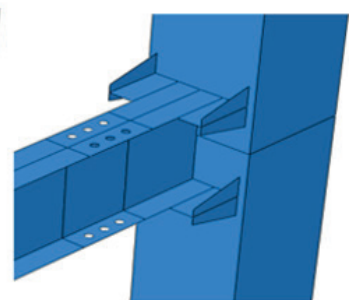

DFC-3-30-C50-B45

Fig. 8 An example of the various connections examined in this study

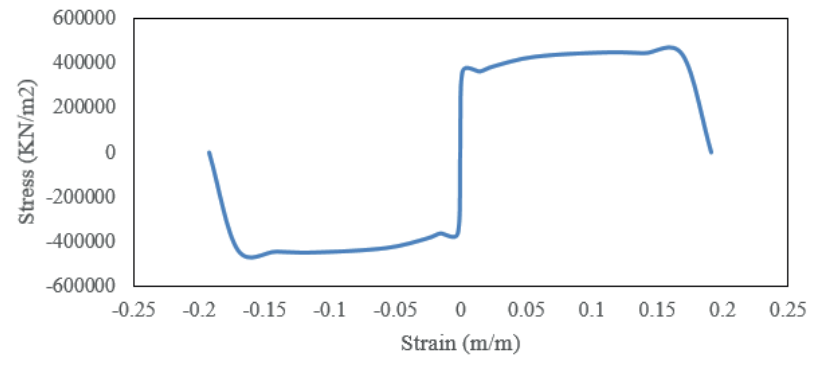

Fig. 9 Steel stress-strain graph

Table 6 The steel properties

\begin{tabular}{lcc}
\hline Special Weight & 7796 & $\mathrm{~kg} / \mathrm{m}^{3}$ \\
Modulus of elasticity & $2.01 \times 1010$ & $\mathrm{~kg} / \mathrm{m}^{2}$ \\
Poisson's Ratio & 0.3 & \\
Shear modulus & $8.077 \times 109$ & $\mathrm{~kg} / \mathrm{m}^{2}$ \\
Stress yields & $3.7 \times 107$ & $\mathrm{~kg} / \mathrm{m}^{2}$ \\
Ultimate tension & $107 \times 5.2$ & $\mathrm{~kg} / \mathrm{m}^{2}$ \\
\hline
\end{tabular}

The major objective of connection design is establishing the plastic hinge in reduced beam flange zone and also extension of plastic area by using all of reduced beam section, which cause increment in plastic effective length more than RBS connections with circular shear. In the proposed connection, by considering uniform extension, plastic strain causes delay in rotational-lateral strain and resist against instability in the reduced area length than in RBS connection with circular shears. In order to find the proper plastic hinge, the reduced part of beam flange must be a definite percentage of plastic moment in beam. Which is calculated by the following formula [13] (Show on Fig. 10).

$\frac{M_{1}}{Z_{1}}=\frac{M_{2}}{Z_{2}}=\frac{M_{3}}{Z_{3}}=\frac{M_{i}}{Z_{i}}$

Which in this formula $M$ is reduced moment used to design holes in section for modifying the beam function for a fuse-like element and its formula is mentioned below. Also $Z$ is the base for plastic section of beam in reduced area and is shown in the following formula.

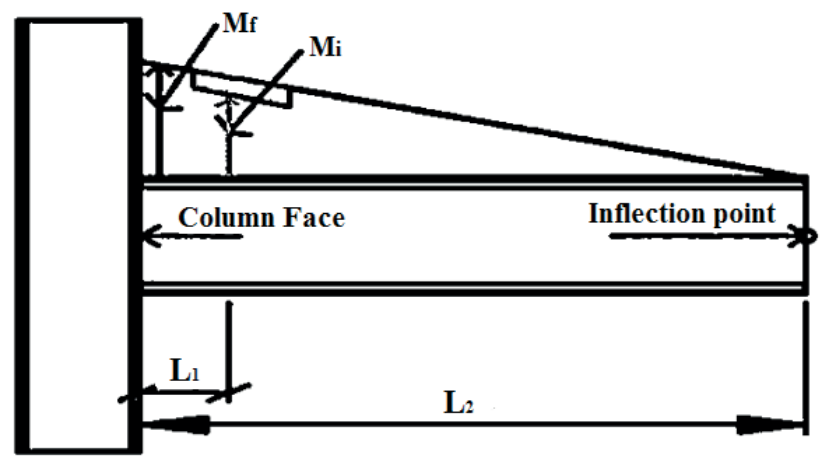

Fig. 10 Calculated moment in reduced area [13]

Table 7 Sections used for 6-storey frame (dimensions in $\mathrm{mm}$ )

\begin{tabular}{lcccc}
\hline Story & $1 \& 2$ & 3 & 4 & 5 \\
\hline Beam & IPE360 & IPE360 & IPE300 & IPE300 \\
Column (BOX) & $250 \times 250 \times 15$ & $250 \times 250 \times 10$ & $250 \times 250 \times 10$ & $220 \times 200 \times 10$ \\
\hline
\end{tabular}




$$
\begin{aligned}
& M_{i}=\alpha M_{p r}\left(\frac{\frac{L}{2}-L_{i}}{\frac{L}{2}}\right) \\
& M_{p r}=C_{p r} R_{y} Z_{b} F_{y} \\
& Z_{i}=Z_{b}-2 D_{i} b_{f}\left(d_{b}-b_{f}\right)
\end{aligned}
$$

\section{Results}

Results are not fully presented due to their large amount, therefore, only one representative of each model is shown and finally, in next section, all major results are discussed. Table 3 shows the results of RBS-C50-B45, in Table 4 DFC-C50-B45 to DFC-C50-B45 is shown and Table 5 shows DFCV-C50-B45.

After modeling, loading and analysis of models, moment-rotation Hysteresis curves are obtained for each model. The surface beneath these curves shows potential of connection for energy absorption. And the more it is, the more it absorbs energy. Plastic strain equivalent of (PEEQ) is used to analyze the plastic hinge formation zone which these amounts are calculated on column face on a lateral strip of beam flange.

In Fig. 11 the Von Mises stress is shown for some of the samples studied.

The compression of the sections has been checked and all the sections have been compressed, and as a result, the buckling in the section has been controlled.

According to the Fig. 12, in the other models including reduced section or drilled beam, the maximum amount of stress was at the hole or in the reduced section. In the proposed connection model, the largest amount is in the attachment. Therefore, the results indicate that in order to form the hinge in the desired location we can use reduced section, drilling and also attaching a part as presented in this article.

As Fig. 12 presents, in model RBS-C50-B45, plastic strain is applied on the reduced part. It is indicated that the connection function in model RBS-C50-B45 is closer to proper function.

It is observed in the model with an attachment part that the attachment part enters the plastic area due to high stresses. The hinge at the connection with an attachment part in the first row of holes has also undergone deformation and diamond shaped in addition to reaching the plastic strain. In the two attachment parts the energy absorption in the connection was great and the stress was balanced between the two parts and this has reduced the damage between the two parts. In the identical-hole model, a plastic strain occurred at the hole and beam web, due to the reduction in cross-section and tolerance a part of stress by the beam web. In the drilled connection with the diamond shaped holes, the stresses are well distributed between the holes and the plastic strain is occurred between the holes uniformly.

One of the features of a connection with diamond shaped hole is the uniform stress distribution between the holes, which results in increasing the load capacity. At the RBS connection, the hinge begins at the middle that has more shear value.

A connection with the drilled beam performs better than the RBS connection, in terms of ability to transfer the plastic hinge from beside the column.

According to Fig. 13, it is observed that in the sample with an attachment part the moment-rotation diagram has an upward trend and increases with increasing in rotation. Because the load capacity is constantly increasing, and it's not totally used. In the RBS diagrams and drilled cross-section diagrams, at first a strength increase is observed in the model and then the strength declines and continues almost constant until the end, the reason could be a decrease in cross-section capacity due to the articulation of a part of the beam flange.

Fig. 14 presents the moment-rotation envelopes of RBS samples.

According to Fig. 15, by increasing the beam cross section, load capacity will increase. Also, by increasing the number of holes in beam flange, the amount of energy absorption of structure and its load bearing capacity will decrease.

By increasing the number of holes with identical diameter, the stiffness will decrease, and it reduces the load capacity of connection. However, the beam with more holes functions better than beams with a single hole. In beams with one hole, the hinge is formed beside the hole but in connections with several holes the hinge is formed between the holes and farther than the column.

According to graphs presented in Fig. 16, in connections which beam section is stronger, the energy absorption is also more, and DFCV model with IPE450 resist the moment almost $50 \%$ more than the samples with IPE300 and IPE270.

By comparing Fig. 17, it can be seen that in the connection where the beam cross section was stronger, the energy absorption was also higher and the ND model with IPE450 cross section was almost $50 \%$ more tolerant than the samples with IPE360 cross section. 


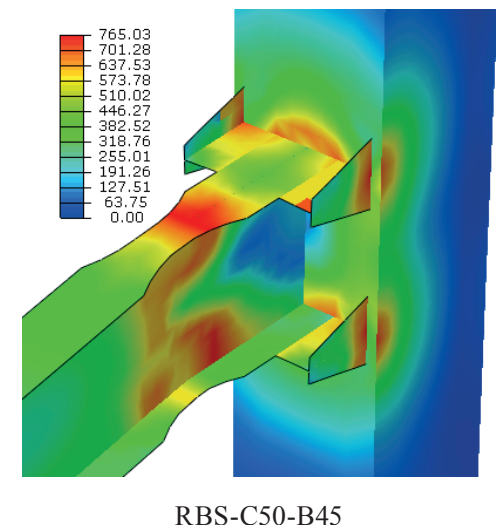

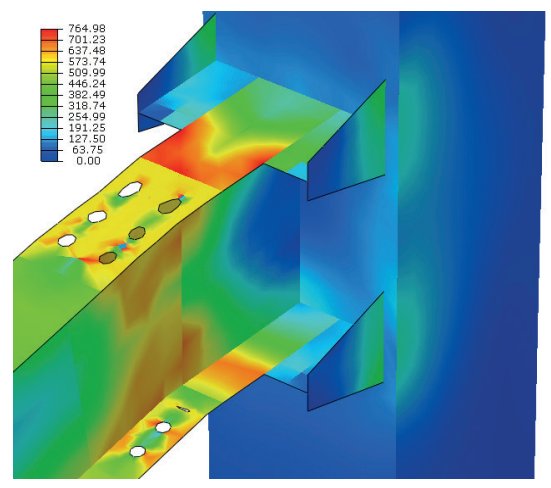

DFC-1-30-C50-B45

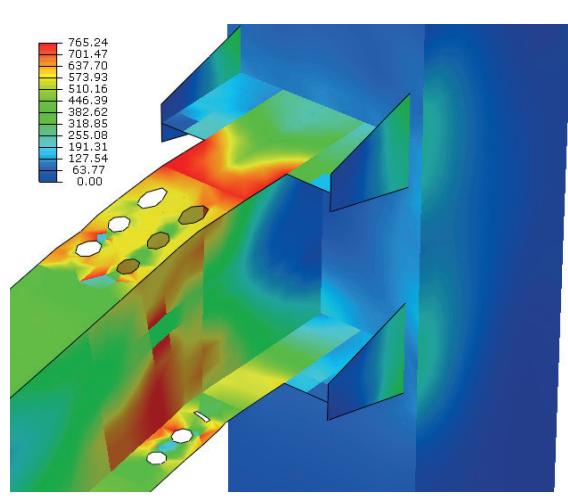

DFC-3-40-C50-B45

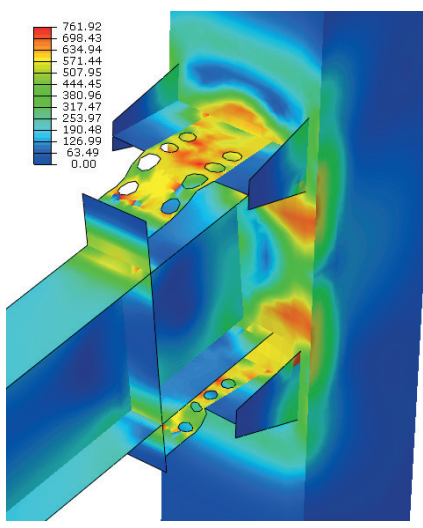

ND-C50-B45-1

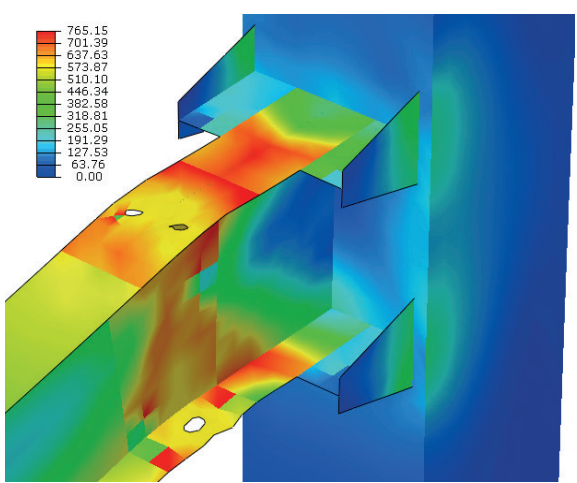

DFC-3-30-C50-B45

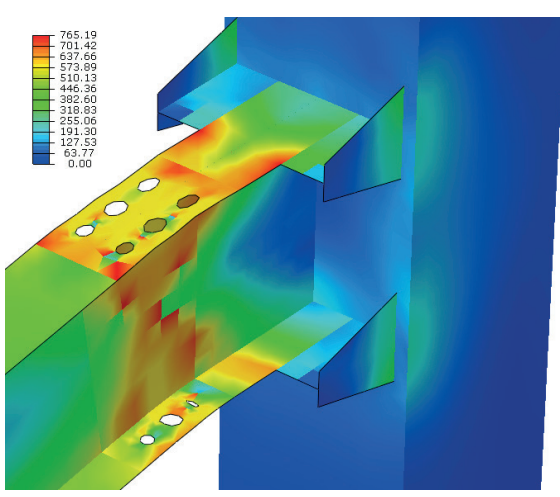

DFCV-C50-B45

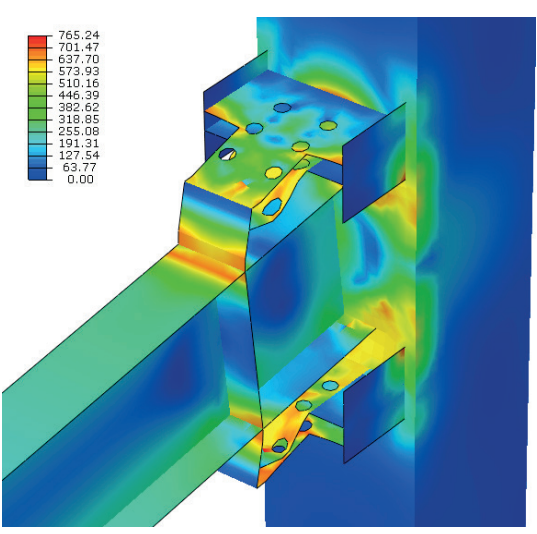

ND-C50-B45-2

Fig. 11 Comparison of the Von Mises stresses in models (unit is MPa) 


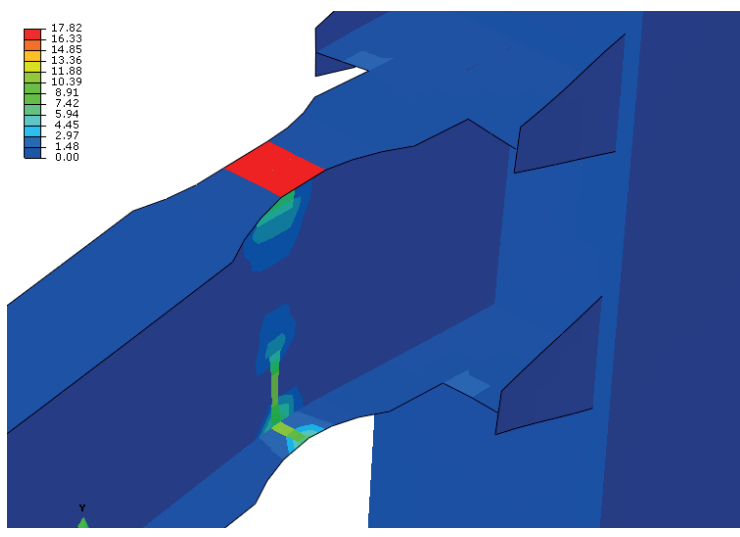

(a) RBS-C50-B45

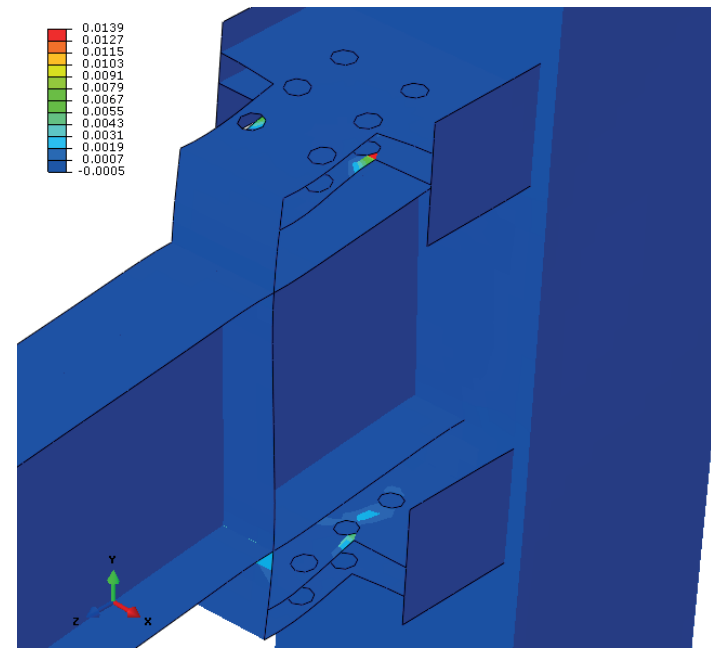

(c) With two attachment parts

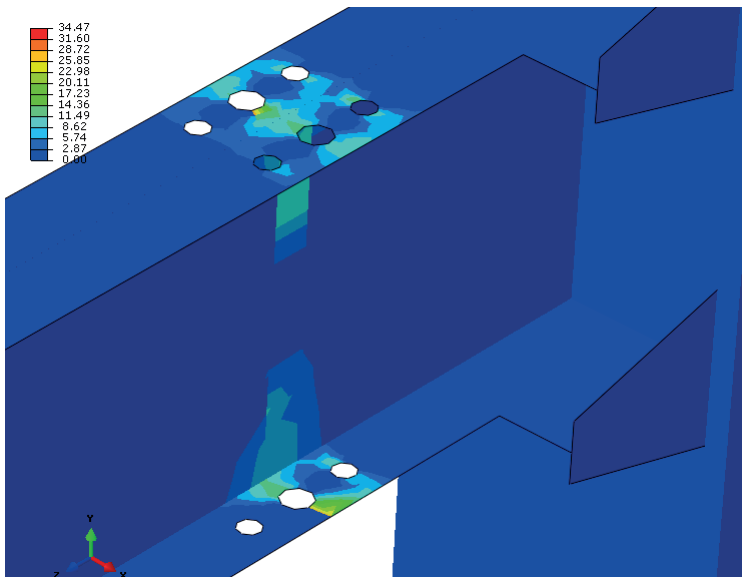

(e) DFCV-C50-B45

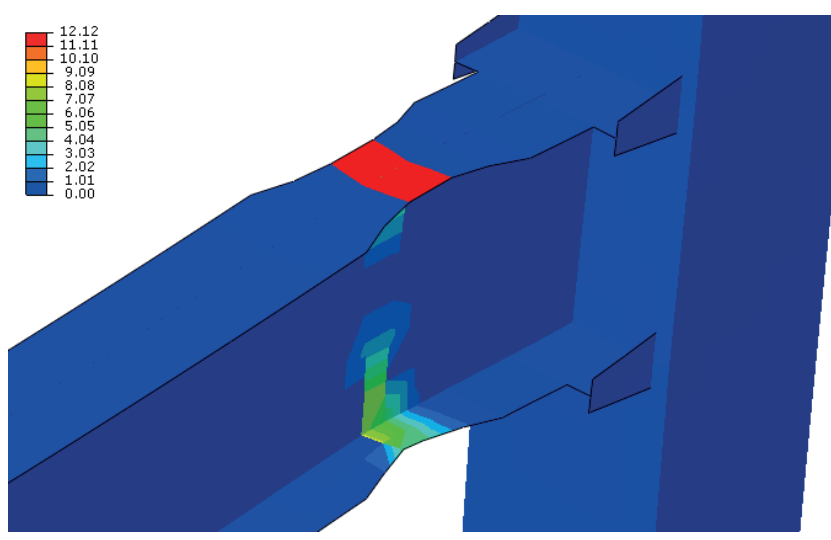

(b) RBS-C25-B30

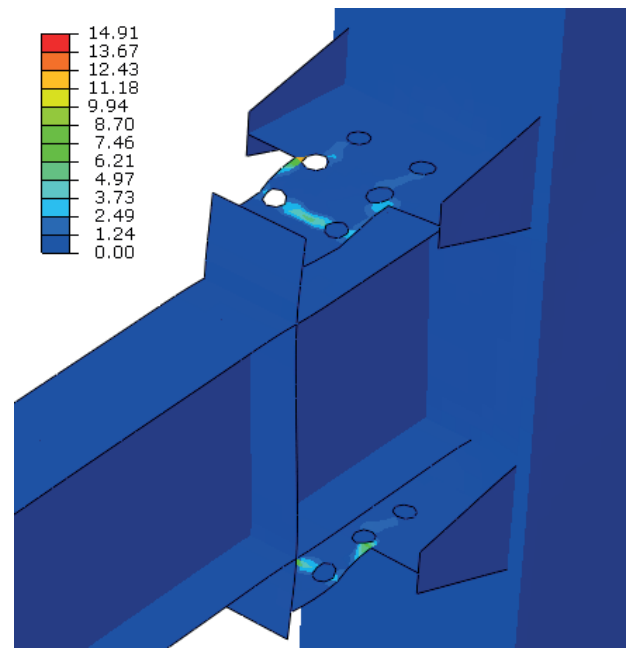

(d) With one attachment part

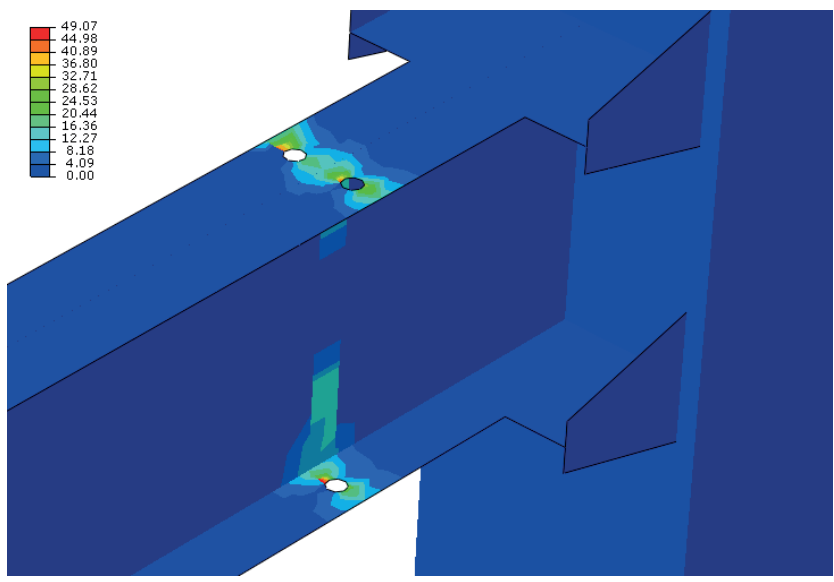

(f) DCF-C50-B45

Fig. 12 The plastic strain in connection zone (unit is MPa)

Fig. 18 shows the hysteresis diagrams of the different models.

By comparing the hysteresis diagram, it can be seen that in the new attachment part, the strength increased as the load increased but in the other models the strength was almost constant, one of the reasons is that in the model, the load capacity of both attachment part and the beam is used, when the attachment part is articulated the load capacity of beam will be used.

According to Fig. 19, the rotational stiffness of drilled models is more than the RBS models. Moreover, stiffness of drilled models with variable diameters is more than 

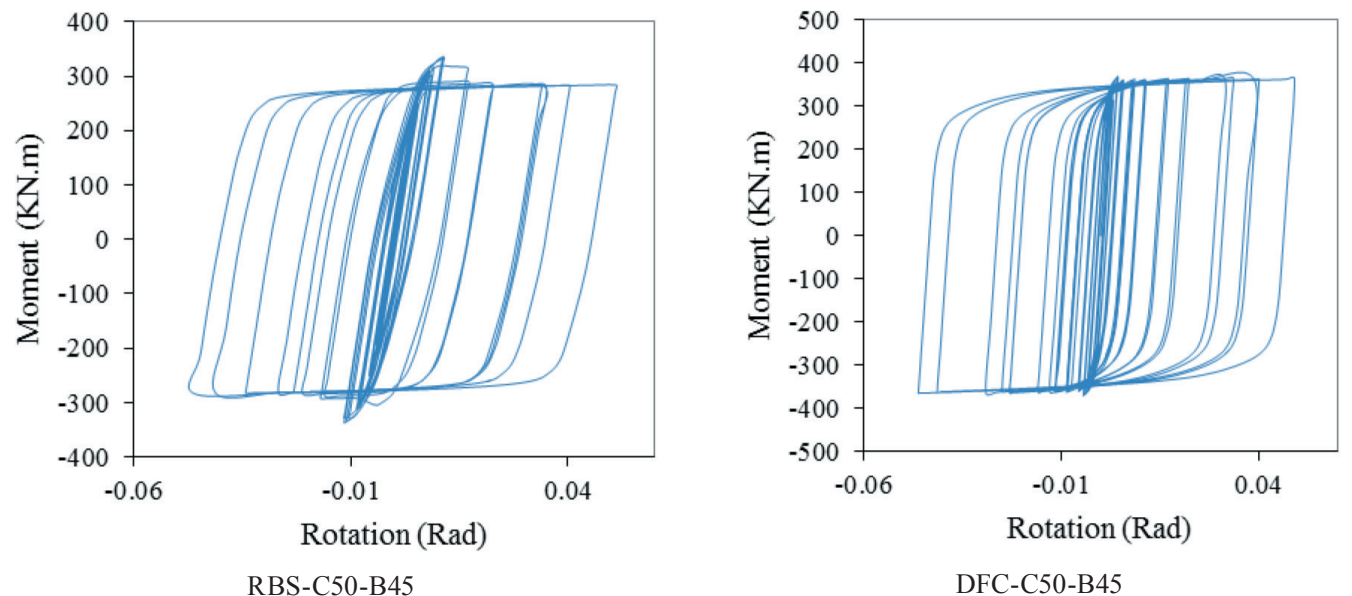

DFC-C50-B45

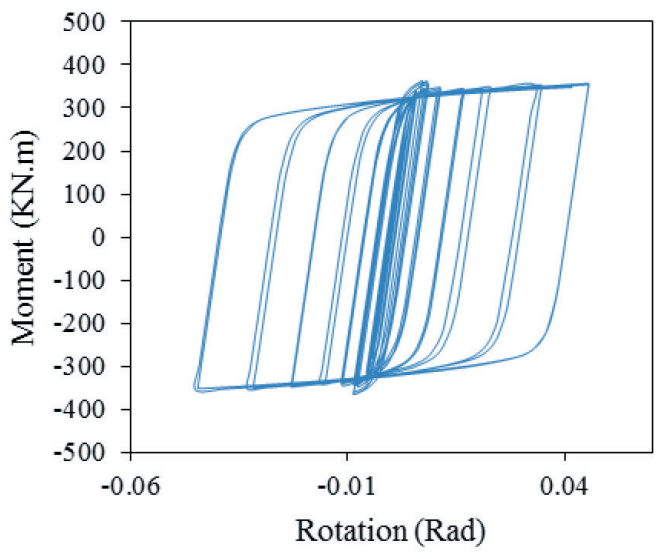

DFCV-C50-B45

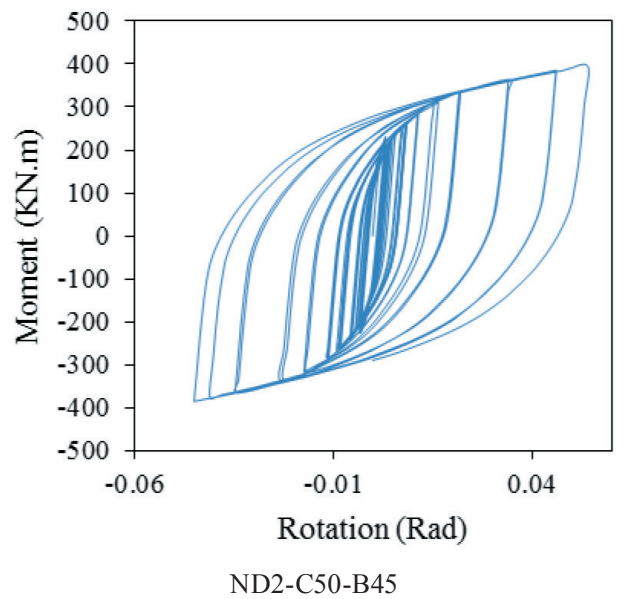

Fig. 13 Moment-rotation diagram of RBS-C50-B 45

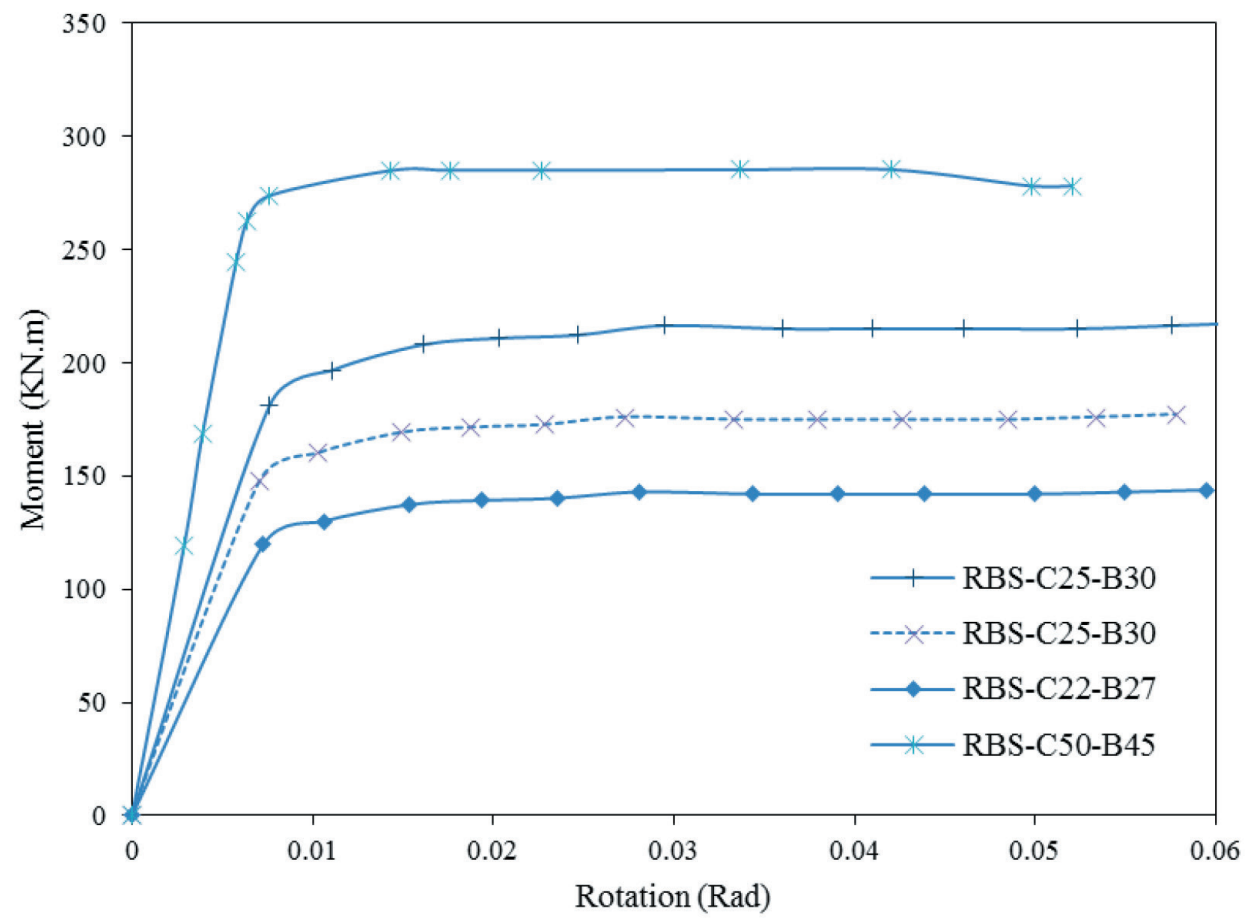

Fig. 14 The moment-rotation envelopes of RBS samples 


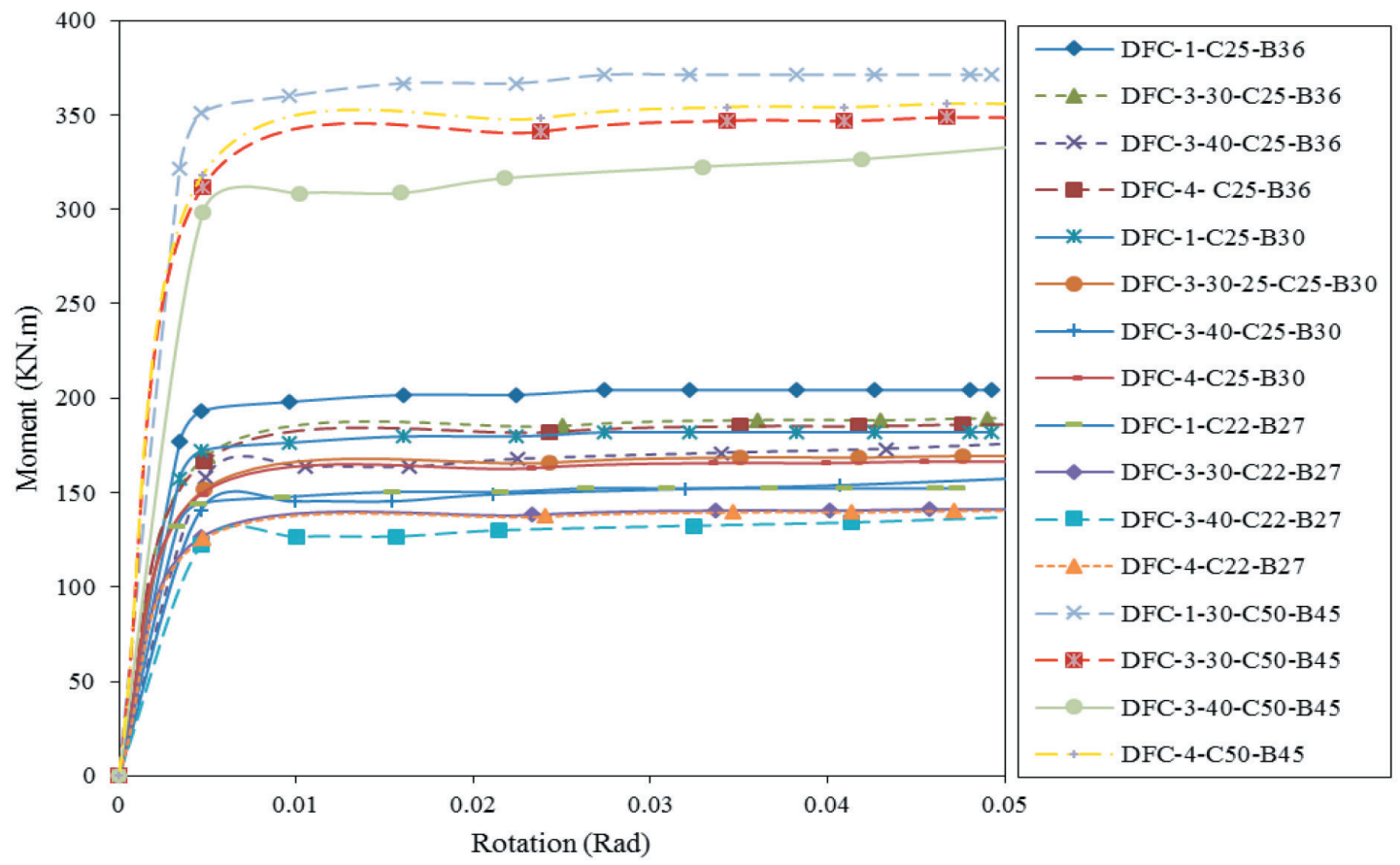

Fig. 15 Moment-rotation diagram for the DFC model

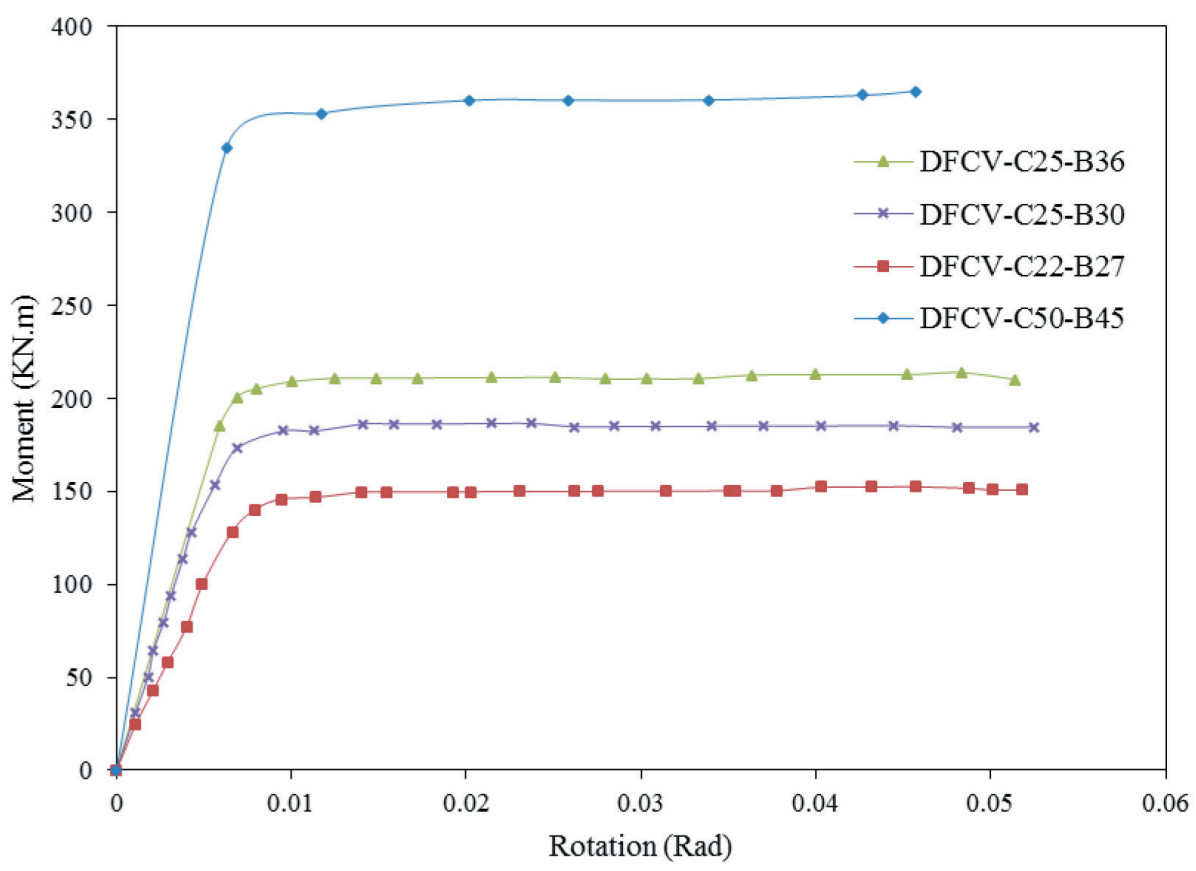

Fig. 16 The envelope moment-rotation for all DFCV models

other models. On the other hand, the stiffness obtained for drilled models with different diameters is approximately $30 \%$ to $40 \%$ higher than other similar drilled models. By comparing the results of the proposed connection with the rest of the connections, it can be seen that the rotation stiffness of the introduced connection was higher than the rest of the connections and in this respect it performed better than other introduced connections.

\subsection{Connections in steel moment frame}

The frames are named according to Table 8. This table shows the models studied in this paper and also the rigid connection (MR) model which exist in the software which is commonly used by engineers. In this connection model, moment transformation ability, shear, and axial force in connection are completely considered in software. Therefore, this model is used for comparing the 


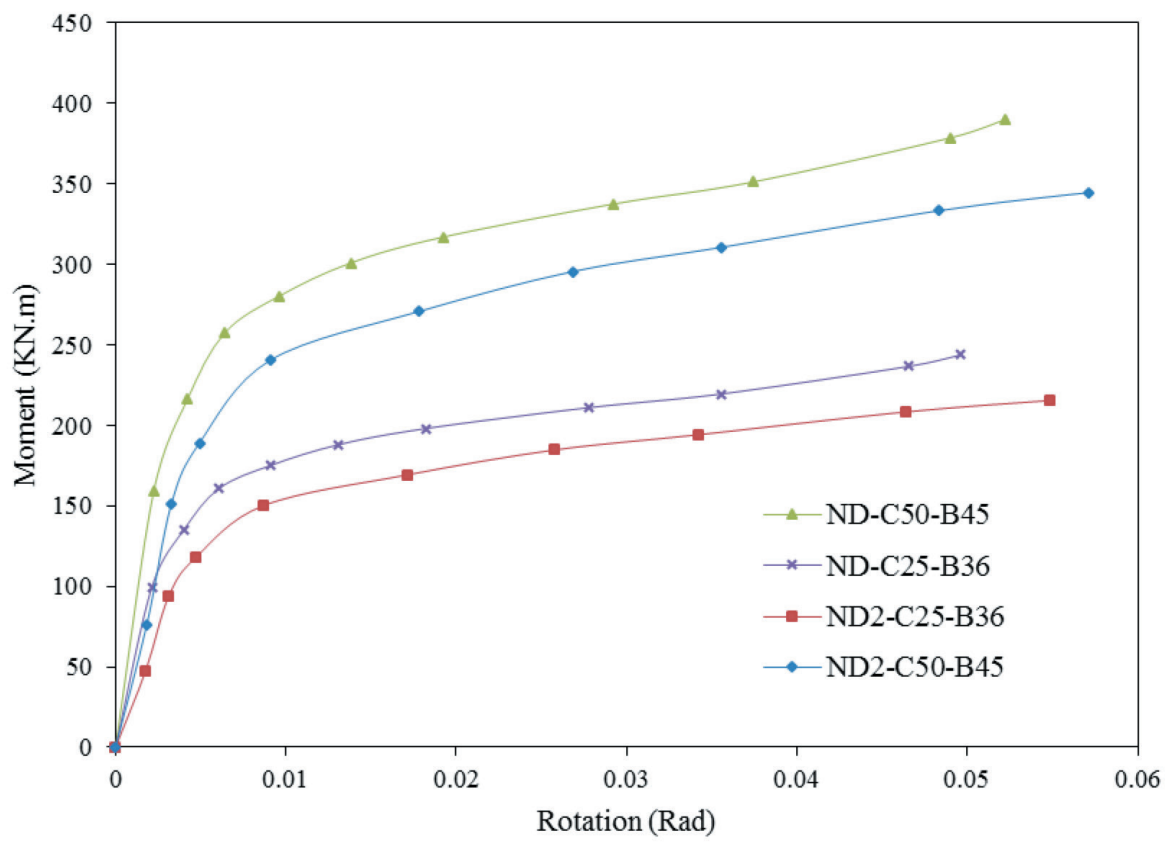

Fig. 17 The envelope moment-rotation for all ND models

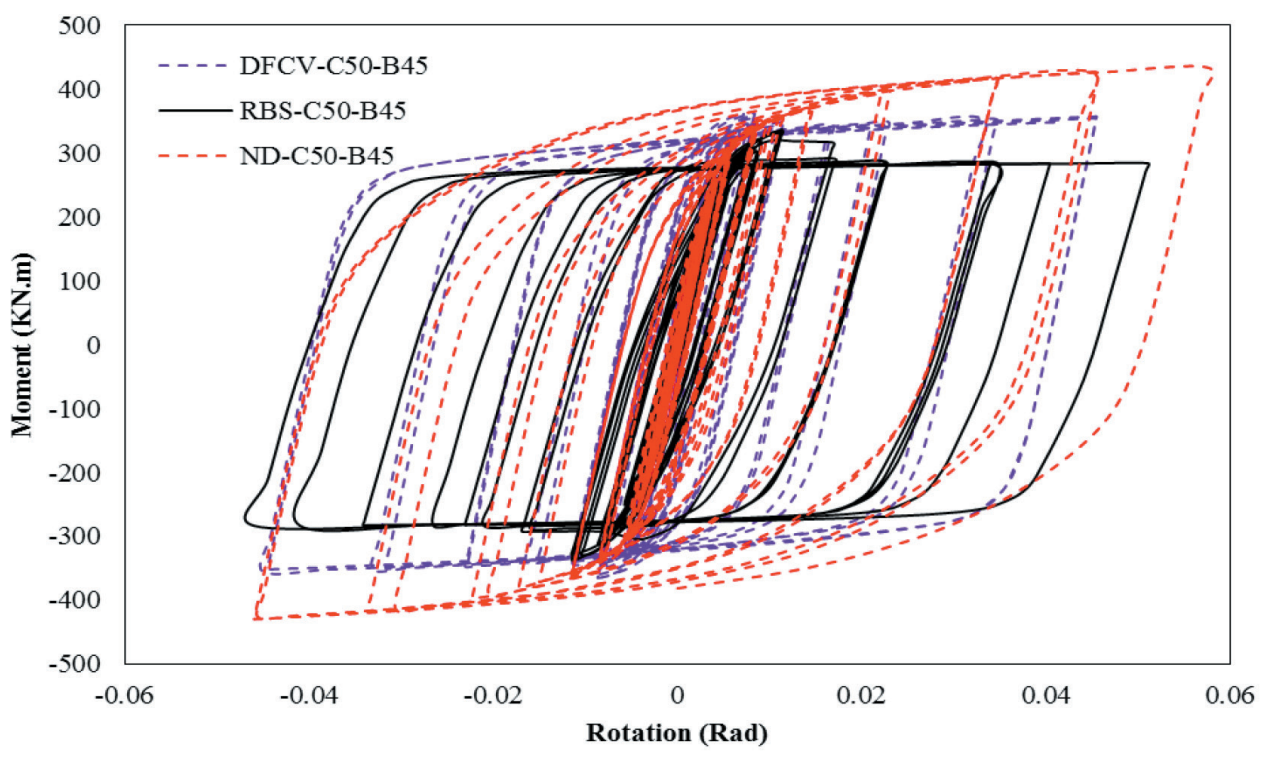

Fig. 18 Comparison of hysteresis graphs

real behavior with behavior that is presented by software. Other connections are related to this paper. The results obtained from frame models by SAP2000 are as follows:

In Table 8, envelope pattern is based on first mode and has a uniform load. For dead and live load, two load combinations are considered: one of them just 0.9 dead load and 1.1 dead load plus 1.1 live load for the other one. Five different connections like rigid connection, RBS, DFC, are also used for applying the panel zone in frames and are described by a frame name. In MR-Uni-1 frame, 'MR' is the first part of the name meaning completely rigid connections, 'Uni' means enveloped by applied uniform load and the number 1 means dead load with 90 percent Association.

In this section, 5 different frame models are analyzed, which their connections are described above. Five frames are founded as frames with rigid connection and frames with connection and stiffness based on above models, which include DFC, RBS, DFCV, and ND. Nonlinear static analysis of the frame is carried out and is applied on frame based on uniform load imposing and envelope first mode based load pattern. 


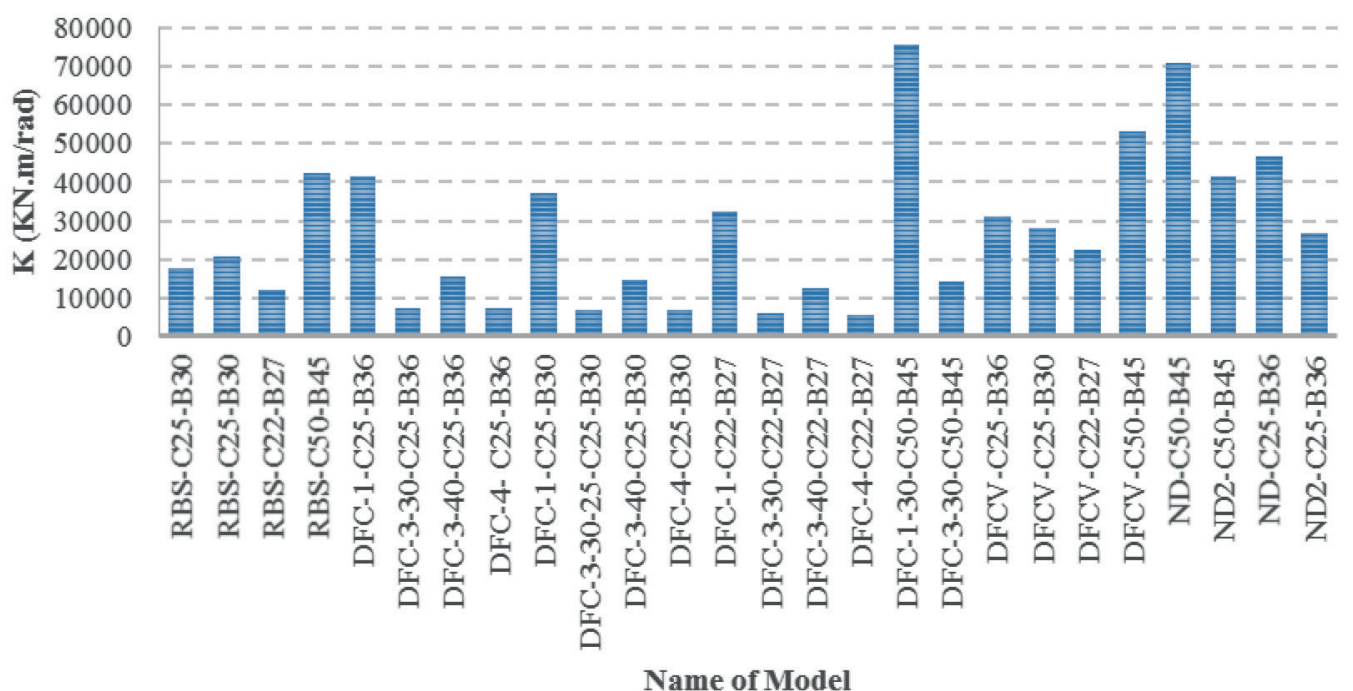

Fig. 19 The results of rotational stiffness

Table 8 Naming of the studied frames

\begin{tabular}{lccccccc}
\hline \multicolumn{2}{l}{ Loading pattern for Push } & \multicolumn{3}{c}{ Load Case } & \multicolumn{3}{c}{ Connection type } \\
\hline Uniform Load & Mode & 0.9 Dead & 1.1(Dead + Live) & rigid & RBS & DFC & DFCV \\
Uni & Mode & 1 & 2 & MR & RBS & DFC & DFCV \\
\hline
\end{tabular}

As Fig. 20 presents, in rigid connection (MR), the formed hinges on column are more critical and also more in number than RBS and drilled models. The formed hinge in column is damaged more because rigid connection has transformed all moment and shear. And energy absorption is not taken in hinge zone. Proposed connection behaves better in forming hinges on beam and column than other models.

By investigating the hinges formed in the frame under study, it is observed that in terms of damage amount in the connection and plastic hinge in a rigid connection (MR) more damage have caused to the connection. Connection with the attachment part, RBS connection and drilled connection absorbed the energy and caused less damage to the column.

In the frame where the connection is rigid, it has more ductility than the other models, because the plastic hinge is formed earlier in this frame and the structure is yielded in less displacement, so the ductility of structure is also increased.

According to Fig. 21, pushover graphs are a little different from each other in different connection models. By comparing the models, it is obtained that models with rigid connection (MR) yield sooner than other models, and by increment in connection rigidity amount, the yield point will delay, so in $\mathrm{NC}$ connection, yield point will happen later than other models. Also, the energy absorption amount in models with rigid connection (MR) is more than other models because of more ductility. And the lowest energy absorption amount is by RBS models.

Table 9 shows the behavior factor for each frame.

The impact of circular holes on seismic behavior of steel beam-column connection is evaluated by using Finite Elements Analysis (FEA) in ABAQUS. Hole properties, including dimension, diameter, number of rows, and spacing is studied. Also, RBS connection is analyzed and compared. After extracting Hysteresis graphs, connection place is determined and also connection stiffness is calculated, then the specified stiffness is applied in SAP2000 by using Panel Zone. So, an accurate behavior of connection is modeled in SAP2000. Finally, rigid frame is modeled in SAP2000 and is compared to real connection behavior.

\section{Conclusions}

This study evaluates the effect of different connections on behavior of steel moment frames. The evaluated connections are as follows: Rigid connections (MR), RBS, DF connection, drilled connection with variable diameter and the proposed connection. The connection is modeled using ABAQUS Finite Elements. The connection is modeled in ABAQUS software with all details, then the moment-rotation charts are calculated. Finally, Finite Elements Modeling (FEM) is utilized to calculate the stiffness for each connection. Steel moment frame is modeled in SAP, 


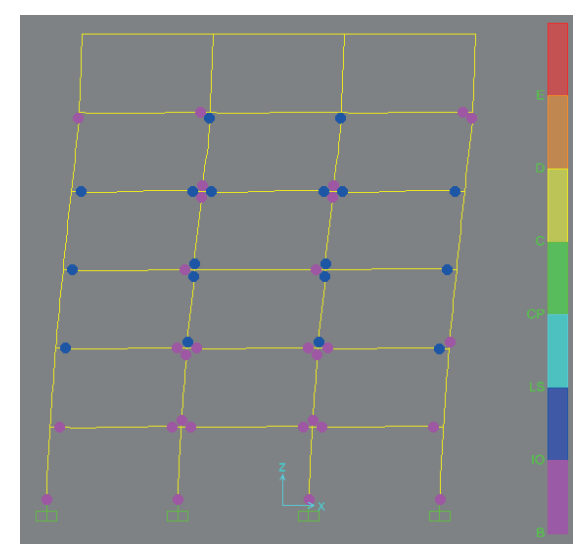

(a)MR

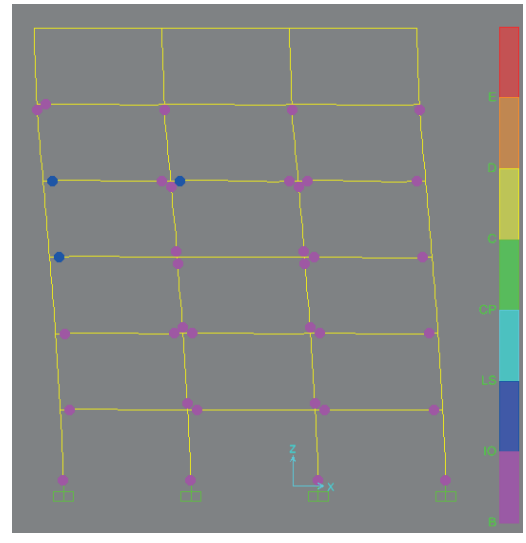

(b) RBS

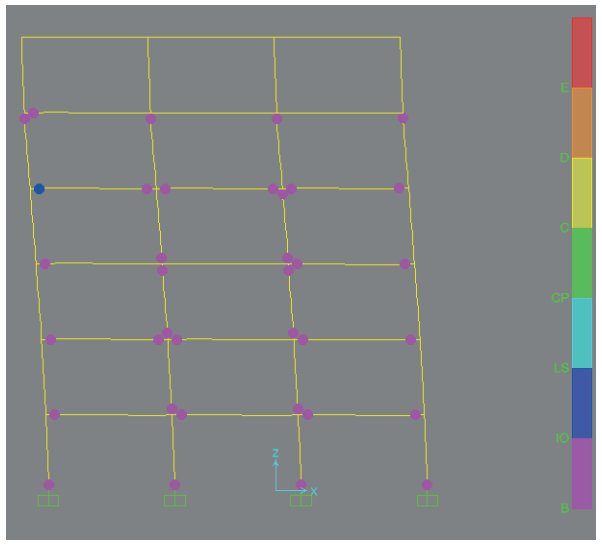

(c)DFC

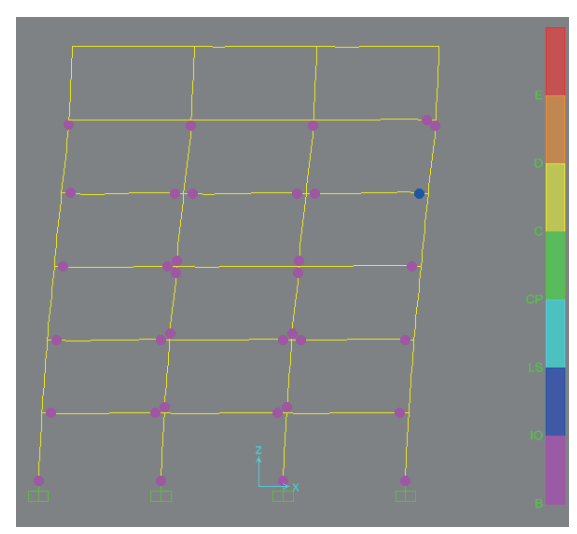

(d) DFCV

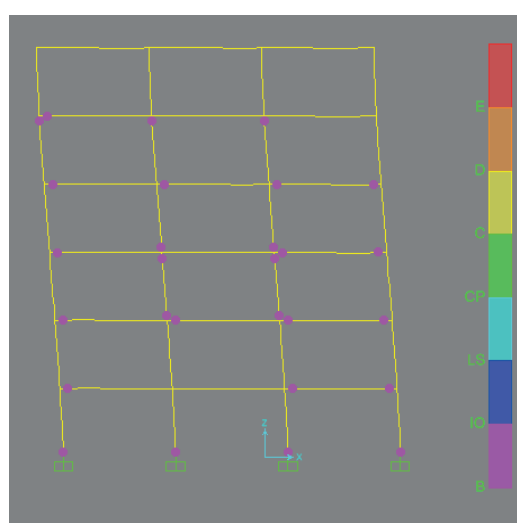

(e) Proposed connection (ND)

Fig. 20 (a, b) presents formed hinges on the frame with rigid connection and RBS connection based on first mode load pattern and 0.9 of dead load

and stiffness is calculated with Finite Elements Analysis of ABAQUS and is used for panel zone. In this paper, the criterion for comparing the behavior of different connections of the hysteresis diagram is the formation of plastic joint, plastic strain, equivalent plastic strain and energy absorption, which is obtained from graphs and graphical shapes.

The results obtained from this research are as follows:

- The drilled connections behavior indicates that drilled connection and connections which contain diamond-shaped holes (two end holes are smaller, and the middle hole is bigger) has more rotational stiffness than RBS.

- Frames behavior indicates that if the connection is rigid, it shows a better non-linear static behavior than other connections. For connections with attachment part, the pushover graph of load bearing, energy absorption and yield point is better than other models. In next level, there is drilled sample with diamond shaped hole and then drilled sample with identical diameter and finally the RBS samples.
- According to the results in samples with attachment part and also in next level connections with variable hole diameter, the energy absorption was higher.

- RBS and drilled connection with variable diameter show that due to reduction in beam flange, local buckling is happened in the position, and it is because of slenderness created in section and also decrement of beam flange stiffness. However, this weak point is not seen in drilled connection with variable diameter. So, this could be another excellence of drilled section connections.

- The proposed connection in this article shows better performance than other options studied in this paper. In the proposed connection the hinge is occurred in attachment part mounted at the connection. Therefore, by replacing this part we can re-used the desired beam, and this is one of this connection's benefits.

- In the proposed, connection it has been attempted to insert three or five holes, leading to the placement of the plastic strain and hinge in the cross attachment part. 


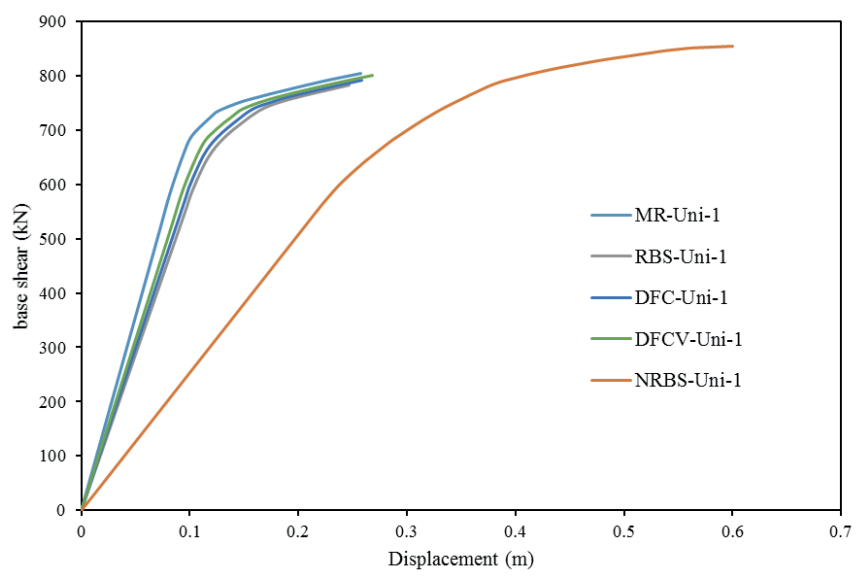

(a) Uniform load pattern based on $0.9 \mathrm{DL}$

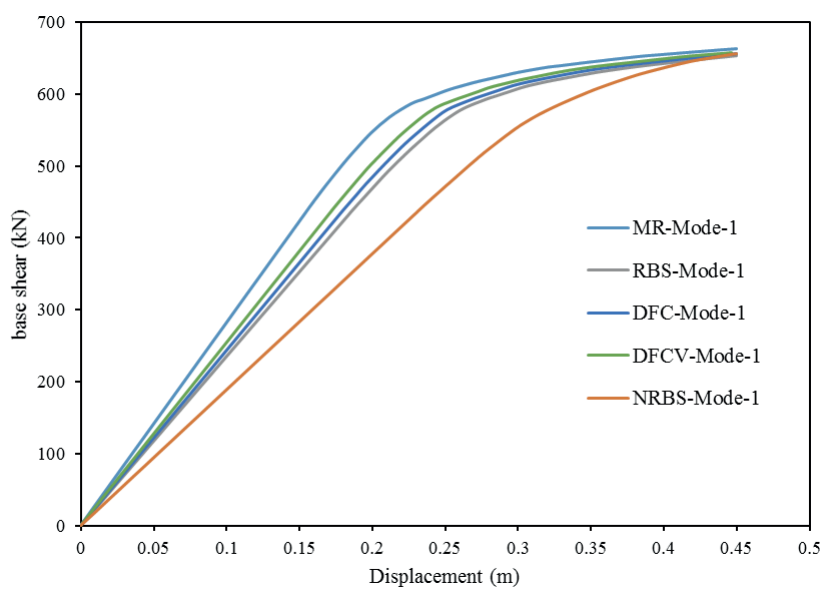

(c) Modal load pattern based on $0.9 \mathrm{DL}$

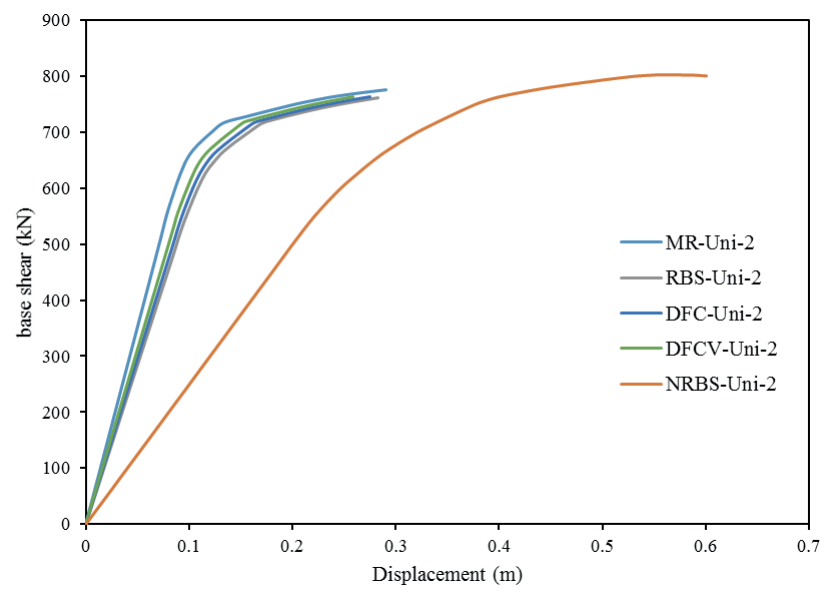

(b) Uniform load pattern based on 1.1(DL+LL)

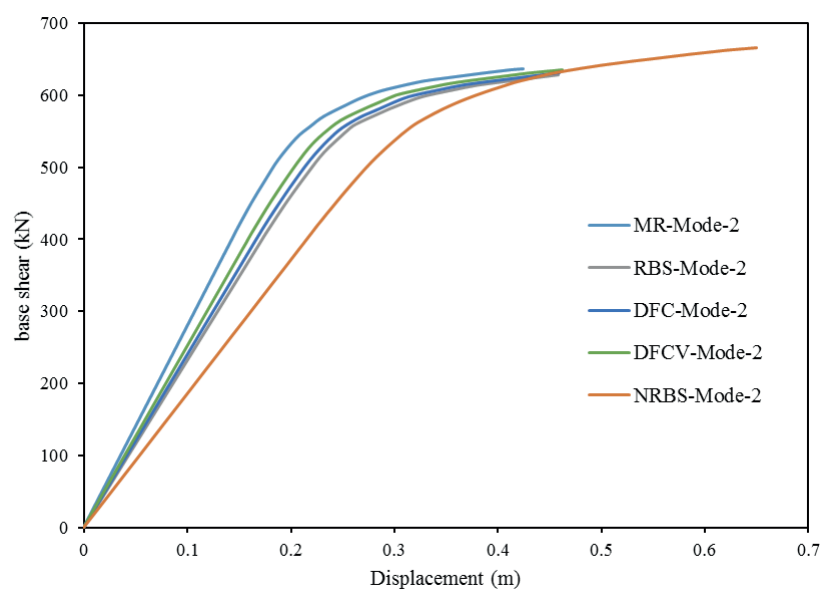

(d) Modal load pattern based on 1.1(DL+LL)

Fig. 21 presents the comparison of pushover graphs for all frames with various connections

- By examining the nonlinear behavior of the proposed connection in the moment frame, it is observed that the initial yield of this type of connection occurred at a larger displacement than the rest of the models, indicating that this type of connection is resistant against loads at a larger displacement (Almost $40 \%$ more than most other models) start to damage and plasticize.

\section{Reference}

[1] Youssef, N. F. G., Bonowitz, D., Gross, J. L. "A Survey of Steel Moment-Resisting Frame Buildings Affected by the 1994 Northridge Earthquake", Building and Fire Research Laboratory National Institute of Standards and Technology, Gaithersburg, MD, USA, Rep. NISTIR 5625, 1995. [pdf] Available at: https://nvlpubs. nist.gov/nistpubs/Legacy/IR/nistir5625.pdf

[2] FEMA "State of the Art Report on Connection Performance", Federeal Emergency Management Agency, Federal Emergency Management Agency, Hyattsville, MD, USA, Rep. FEMA-355D, 2000. [pdf] Available at: https://www.nehrp.gov/pdf/fema355d.pdf
Table 9 The behavior factor for each frame

\begin{tabular}{lccccc}
\hline \multirow{2}{*}{$\begin{array}{l}\text { Pattern for } \\
\text { loading for push }\end{array}$} & MR & RBS & DFC & DFCV & ND \\
\hline Uni-1 & 4.38 & 4.15 & 3.9 & 4.38 & 4.2 \\
Uni-2 & 4.94 & 4.15 & 3.85 & 4.1 & 4 \\
Mode-1 & 3 & 2.5 & 2.53 & 2.7 & 2.65 \\
Mode-2 & 2.8 & 2.45 & 2.55 & 2.75 & 2.7 \\
\hline
\end{tabular}

[3] Engelhardt, M. D., Venti, M. J., Fry, G. T., Jones, S. L., Holliday, S. D. "Behavior and Design of Radius Cut Reduced Beam Section Connections", SAC Joint Venture, Richmond, CA, USA, Rep. SAC/BD-00/17, 2000. [pdf] Available at: https://store.atcouncil. org/index.php?dispatch=products.view\&product_id=132

[4] Crisan, A., Dubina, D. "Bending-shear interaction in short coupling steel beams with reduced beam section", Journal of Constructional Steel Research, 122, pp. 190-197, 2016. https://doi.org/10.1016/j.jcsr.2016.03.020 
[5] Tahamouli Roudsari, M., Jamshidi, K. H., Mohebi Zangeneh, M. "Experimental and Numerical Investigation of IPE Reduced Beam Sections with Diagonal Web Stiffeners", Journal of Earthquake Engineering, 22(4), pp. 533-552, 2018. https://doi.org/10.1080/13632469.2016.1234422

[6] Tahamouli Roudsari, M., Jamshidi, K. H., Moradi, S. H. "Experimental and Numerical Assessment of Reduced IPE Beam Sections Connections with Box-Stiffener", International Journal of Steel Structures, 18(1), pp. 255-263, 2018.

https://doi.org/10.1007/s13296-018-0319-0

[7] Montuori, R., Sagarese, V. "The use of steel rbs to increase ductility of wooden beams", Engineering Structures, 169, pp. 154-161, 2018. https://doi.org/10.1016/j.engstruct.2018.05.024

[8] Uang, C.-M., Yu, Q.-S. "Kent", Noel, S., Gross, J. "Cyclic Testing of Steel Moment Connection Rehabilitated with RBS or Welded Haunch", Journal of Structural Engineering,126(1), pp. 67-78, 2000. https://doi.org/10.1061/(ASCE)0733-9445(2000)126:1(57)

[9] Qian, J., Yu, H., Yan, F., Dong, H., Li, J., Liu, Y. "Experimental study on full-scale steel beam-to-column moment connections", Earthquake Engineering and Engineering Vibration, 4(2), pp. 311323, 2005.

https://doi.org/10.1007/s11803-005-0015-x

[10] Tsai, K. C., Chen, C.-Y. "Performance of Ductile Steel Beam - Column Moment Connections", presented at Eleventh World Conference on Earthquake Engineering, Acapulco, Mexico, June, 23-28, Paper No. 405, 1996.

[11] Lee, S. L., Han, S. E., Noh, S. Y., Shin, S.-W. "Deformation Capacity of Reduced Beam Section Moment Connection by Staggered Holes", In: Proceedings of the International Conference on Sustainable Building Asia, Seoul, Korea, 2007, pp. 1067-1072.

[12] Farrokhi, H., Danesh, F., Eshghi, S. "A modified moment resisting connection for ductile steel frames (Numerical and experimental investigation)", Journal of Constructional Steel Research, 65(10-11), pp. 2040-2049, 2009.

https://doi.org/10.1016/j.jcsr.2009.04.019
[13] Vetr, M. G. H., Miri, M., Haddad, A. "Seismic Behavior of a New Reduced Beam Section Connection by Drilled Holes Arrangement (RBS_DHA) on the Beam Flanges through Experimental Studies", presented at 15th World Conference on Earthquake Engineering (WCEE), Lisbon, Portugal, Sept. 24-28, 2012.

[14] Vajdian, M., Mehdi Zahraei, S., Mirhosseini, S. M., Zeighami, E. "Investigation of Seismic Performance of (RBS) and Drilled Flange Connection (DFC) Containing rhombus Shaped Hole in Steel Moment Frames", Australian Journal of Civil Engineering, 2020.

https://doi.org/10.1080/14488353.2020.1771664

[15] Maleki, M., Jazany, R. A., Ghobadi, M. S. "Seismic Fragility Assessment of SMRFs with Drilled Flange Connections using Ground Motion Variability", KSCE Journal of Civil Engineering, 23(4), pp. 1733-1746, 2019.

[16] Özkılıç, Y. O. "A new replaceable fuse for moment resisting frames: Replaceable bolted reduced beam section connections", Steel and Composite Structures, 35(3), pp. 353-370, 2020. https://doi.org/10.12989/scs.2020.35.3.353

[17] Fanaie, N., Moghadam, H. S. "Experimental study of rigid connection of drilled beam to CFT column with external stiffeners", Journal of Constructional Steel Research, 153, pp. 209-221, 2019. https://doi.org/10.1016/j.jcsr.2018.10.016

[18] Krawinkler, H. "Guidelines for cyclic seismic testing of components of steel structures", Applied Technology Council, Redwood City, CA, USA, ATC-24, 1992. 